\title{
Mesenchymal stem cells in arthritis: role of bone marrow microenvironment
}

\author{
Christian Jorgensen ${ }^{1,2 *}$ \\ See related research by Mohanty et al., http://arthritis-research.com/content/12/4/R149
}

\begin{abstract}
Based on their capacity to suppress immune responses, multipotent mesenchymal stromal cells (MSCs) are intensively studied for regenerative medicine. Moreover, MSCs are potent immunomodulatory cells that occur through the secretion of soluble mediators including nitric oxide, transforming growth factor beta, and HLAG5. The MSCs, however, are also able to express inflammatory mediators such as prostaglandin $\mathrm{E}_{2}$ or IL-6. MSCs in the bone marrow are in close contact with T cells and B cells, and they regulate immunological memory by organizing defined numbers of dedicated survival niches for plasma cells and memory T cells in the bone marrow. The role of MSCs in arthritis remains controversial in some studies, murine allogeneic MSCs are able to decrease arthritis; in other studies, MSCs worsen the local inflammation. A recent paper in Arthritis Research and Therapy shows that bone marrow MSCS have decreased osteoblastic potential in rheumatoid arthritis, which may be related to chronic inflammation or to loss of expression of IL-1 receptor agonist. That article raises the importance of the bone marrow microenvironment for MSC biology.
\end{abstract}

Mesenchymal stem cells or multipotent mesenchymal stromal cells (MSCs) have been identified in the bone marrow as well as in other tissues of the joint, including adipose tissue, synovial tissue, periosteum, perichondrium, and cartilage. These cells are characterized by their phenotype and their ability to differentiate into three lineages, chondrocytes, osteoblasts and adipocytes. Importantly, MSCs are also potent modulators of immune responses, exhibit healing capacities, improve

\footnotetext{
*Correspondence: christian.jorgensen@inserm.fr

IInserm, U844, Montpellier F-34091, France

Full list of author information is available at the end of the article
}

angiogenesis and prevent fibrosis. The recent work of Mohanty and coworkers shows the changes in the bone marrow niche in the course of arthritis and the loss of osteoblastic differentiation in this model [1].

\section{Mesenchymal stem cells are present in the arthritic joint}

MSCs are defined according to three criteria: their property to adhere to plastic, their phenotype (CD73+,

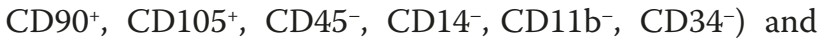
their capacity to differentiate into three lineages: chondrocytes, osteoblasts and adipocytes [2]. Besides these factors, MSCs display a broader differentiation potential. They can differentiate into myocytes, tendinocytes, ligamentocytes, cardiomyocytes, and other cell types [3]. Their differentiation potential is largely dependent on environmental factors; in particular, specific growth factors - but, as an example, hypoxia and the threedimensional environment are also pivotal factors that probably help to support the chondrocytic phenotype. MSCs have been identified in the bone marrow, but also in other tissues of the joint including adipose tissue, periosteum, perichondrium, synovial tissue and cartilage [4-7].

\section{Immunomodulatory effects of mesenchymal stem cells}

In addition to their potential for tissue repair, MSCs are potent modulators of immune responses, having antiproliferative and anti-inflammatory capacities. Although terminally differentiated stromal cells, such as fibroblasts, also share some immunosuppressive activities with MSCs, as shown by their ability to suppress in vitro T-cell proliferation [8], they do not exert in vivo the suppressive effect mediated by MSCs. MSC-mediated immunosuppression requires their previous activation by immune cells through proinflammatory cytokines IFNY with TNF $\alpha$ or IL-1 $\beta$ [9]. Moreover, other molecules including indoleamine-2,3-dioxygenase, heme oxidase as well as HLAG5 have been involved in MSC-mediated immunosuppression.

MSCs, however, are also able to express inflammatory mediators such as prostglandin $E_{2}$ or IL-6. The 
production of this enzymatic product of arachidonic acid metabolism is enhanced in MSCs upon TNF $\alpha$ or IFN $\gamma$ stimulation. This may explain why in a particular inflammatory environment MSCs may have a paradoxal effect on immune cells. In the bone marrow niche, another example of the role of MSCs is the production of receptor activator for NF-kB ligand (RankL) and of osteoprotegerin, which will stimulate osteoclast formation from hematopoietic precursor cells and will inhibit bone formation, respectively. Moreover, MSCs regulate immunological memory by organizing defined numbers of dedicated survival niches for plasma cells and memory $\mathrm{T}$ cells in the bone marrow. A distinct subpopulation of MSCs, characterized by the expression of CXCL12 and vascular cell adhesion molecule-1, might provide a survival niche for memory plasma cells [10]. In contrast, another fraction of CXCL12-negative bone marrow MSCs expresses IL-7. These cells are in close contact with memory $\mathrm{CD}^{+} \mathrm{T}$ cells and keep the $\mathrm{T}$ cells quiescent through the effect of IL-7. These results suggest heterogeneity of MSCs in terms of immune and hematopoietic functions, but also suggest that MSCs play a key role to maintain immune homeostasis.

\section{Mesenchymal stem cells and autoimmunity}

In rheumatoid arthritis, using the experimental collageninduced arthritis model, contrasting results are reported. A single injection of MSCs was shown to prevent the occurrence of severe arthritis, which was associated with a decrease in serum proinflammatory cytokines [11]. We have shown that the allogeneic C3H10T1/2 MSC line did not exert a beneficial effect on collagen-induced arthritis [12]. As in other autoimmune models, MSCs were not observed in the target organ. Zappia and collaborators reported the therapeutic efficacy of MSCs in the experimental autoimmune encephalomyelitis murine model of multiple sclerosis [13]. In this model, MSCs decreased the clinical signs associated with demyelinization when injected before or at the onset of disease. The same results were observed in a model of autoimmune diabetes, where MSC injection induced a decrease in mesangial thickening and in macrophage infiltration, resulting in the prevention of pancreatic injury [14].

Stromal cells are no longer second citizens but are firstline players. They appear as major regulatory cells in skeletal tissues controlling inflammation, immune response, fibrosis and tissue regeneration. A better understanding of the interactions between stromal cells and immune cells is required for therapeutic applications and to validate the strong potential of MSCs in rheumatologic diseases. The work presented by Mohanty and colleagues underlines the link between osteoporosis, inflammation and MSCs. The in vivo behavior of MSCs in the context of pathological situations remains to be further studied in rheumatoid arthritis.

\section{Abbreviations}

IFN, interferon; IL, interleukin; MSC, mesenchymal stromal cell; NF, nuclear factor; TNF, tumor necrosis factor.

\section{Competing interests}

The author declares that he has no competing interests.

\section{Author details}

'Inserm, U844, Montpellier F-34091, France. Université Montpellier 1, UFR de Médecine, Montpellier F-34000, France.

Published: 23 August 2010

\section{References}

1. Mohanty ST, Kottam L, Gambardella A, Nicklin MJ, Coulton L, Hughes D, Wilson AG, Croucher PI, Bellantuono I: Alterations in the self-renewal and differentiation ability of bone marrow mesenchymal stem cells in a mouse model of rheumatoid arthritis. Arthritis Res Ther 2010, 12:R149.

2. Djouad F Mrugala D, Noël D, Jorgensen C: Engineered mesenchymal stem cells for cartilage repair. Regen Med 2006, 1:529-537.

3. Pittenger M Vanguri $P$, Simonetti D, Young R: Adult mesenchymal stem cells: potential for muscle and tendon regeneration and use in gene therapy. $J$ Musculoskelet Neuronal Interact 2002, 2:309-320.

4. Djouad F Bony C, Häupl T, Uzé G, Lahlou N, Louis-Plence P, Apparailly F, Canovas F, Rème T, Sany J, Jorgensen C, Noël D: Transcriptional profiles discriminate bone marrow-derived and synovium-derived mesenchymal stem cells. Arthritis Res Ther 2005, 7:R1304-R1315.

5. De Bari C Dell'Accio F, Luyten FP: Human periosteum-derived cells maintain phenotypic stability and chondrogenic potential throughout expansion regardless of donor age. Arthritis Rheum 2001, 44:85-95.

6. Noel D Caton D, Roche S, Bony C, Lehmann S, Casteilla L, Jorgensen C, Cousin B: Cell specific differences between human adipose-derived and mesenchymal-stromal cells despite similar differentiation potentials. Exp Cell Res 2008, 314:1575-1584.

7. Fickert S Fiedler J, Brenner RE: Identification, quantification and isolation of mesenchymal progenitor cells from osteoarthritic synovium by fluorescence automated cell sorting. Osteoarthritis Cartilage 2003, 11:790-800

8. Le Blanc KTammik L, Sundberg B, Haynesworth SE, Ringdén O: Mesenchymal stem cells inhibit and stimulate mixed lymphocyte cultures and mitogenic responses independently of the major histocompatibility complex. Scand $\mathrm{J}$ Immunol 2003, 57:11-20.

9. Rasmusson I: Immune modulation by mesenchymal stem cells. Exp Cell Res 2006, 312:2169-2179.

10. Tokoyoda, K. Zehentmeier S, Hegazy AN, Albrecht I, Grün JR, Löhning M, Radbruch A: Professional memory CD4 ${ }^{+} \mathrm{T}$ lymphocytes preferentially reside and rest in the bone marrow. Immunity 2009, 30:721-730.

11. Augello A Tasso R, Negrini SM, Cancedda R, Pennesi G: Cell therapy using allogeneic bone marrow mesenchymal stem cells prevents tissue damage in collagen-induced arthritis. Arthritis Rheum 2007, 56:1175-1186.

12. Djouad F Fritz V, Apparailly F, Louis-Plence P, Bony C, Sany J, Jorgensen C, Noël $D$ : Reversal of the immunosuppressive properties of mesenchymal stem cells by tumor necrosis factor alpha in collagen-induced arthritis. Arthritis Rheum 2005, 52:1595-1603.

13. Zappia E Casazza S, Pedemonte E, Benvenuto F, Bonanni I, Gerdoni E, Giunti D, Ceravolo A, Cazzanti F, Frassoni F, Mancardi G, Uccelli A: Mesenchymal stem cells ameliorate experimental autoimmune encephalomyelitis inducing T-cell anergy. Blood 2005, 106:1755-1761.

14. Lee RH Seo MJ, Reger RL, Spees JL, Pulin AA, Olson SD, Prockop DJ: Multipotent stromal cells from human marrow home to and promote repair of pancreatic islets and renal glomeruli in diabetic NOD/scid mice. Proc Natl Acad Sci U S A 2006, 103:17438-17443.

doi:10.1186/ar3105

Cite this article as: Jorgensen C: Mesenchymal stem cells in arthritis: role of bone marrow microenvironment. Arthritis Research \& Therapy 2010, 12:135. 